Getúlio de Souza NUNES*

\title{
Reflexões para a prática educativa "paradigma de um conhecimento prudente para uma vida decente"1
}

\section{Resumo}

O estudo enfoca evidências de práticas educativas/sociais que configuraram um novo paradigma analisado à luz dos referenciais teóricos propostos por Boaventura de Souza Santos.

Tal paradigma parece romper com ideologias, valores, crenças, preconceitos etc, imbricados no conhecimento e no contexto social onde se vive e se atua, pois os fundamentos teóricos, conceptuais e epistemológicos atuais não mais se apresentam convincentes. Portanto, há indicações da necessidade de outros fundamentos orientados a uma racionalidade mais plural, na qual o conhecimento seja uma experiência fascinante e emancipatória. As indicações para um paradigma social do conhecimento são as de que: todo conhecimento científico-natural é científico-social; é local e total; é auto-conhecimento e visa constituir em senso comum.

\section{Abstract}

This study focuses the evidences from socioeducacional practices that configure a new paradigm analyzed according to the theorical references proposed by Boaventura de Souza Santos. This paradigm causes ruptures in the ideologies, values, believes, prejudices etc, imbricated into knowledge and the social context where one lives and acts, because the present theorical foundations, conceptual and epistemological, don't become convincing anymore. So, there are evidences of need for other foundations oriented to more plural rationality in which the knowledge be a fascinating and emancipating experience. The indications for a social knowledge paradigm are: all the scientific-cultural knowledge is scientific-social as well; it's local and total; it's self-knowledge and look for constituting in common sense.

\section{A problemática e os propósitos de estudo}

A fragmentação do saber tem representado uma tendência fundamental para a aquisição do conhecimento científico no âmbito do 'paradigma da ciência moderna' considerado paradigma dominante na atualidade, tendo como base a concepção de que a redução dos fenômenos, em partes cada vez menores, proporcionaria ao indivíduo compreensão do todo e, conseqüentemente, domínio sobre a natureza. Essa tendência à fragmentação gera/gerou uma visão dualista/dicotômica/maniqueísta de conhecimento, que tem prevalecido, principalmente em termos escolares, porque distingue cabalmente sujeito/objeto, observador/observado, teoria/prática, individual/social, mente/corpo, objetivo/subjetivo, individual/coletivo, causa/efeito e, subjazendo a essas, uma dissociação crucial entre conhecimento científico/senso comum.

Fatos decorrentes do 'paradigma dominante', mesmo apresentando aspectos positivos, promoveram a 'crise' que se instalou no seu interior, pois, à medida que aumentava o volume e o aprofundamento de conhecimentos nas áreas do saber,

${ }^{1}$ O presente trabalho foi desenvolvido no núcleo de Estudos em Educação e Ciências da UNIMEP sob a orientação da Dra. Rosália M. Aragão e participação dos doutorandos Francisco Eugenio Barrela e Lenice H. de Arruda Silva.

* Doutorando em Educação do PPGE da Universidade Metodista de Piracicaba. Coordenador do curso de Sistemas de Informação das Faculdades Integradas "Campos Salles". Professor da FAC-FITO. 
elevavam-se as limitações de tal paradigma, expondo suas insuficiências estruturais e a fragilidade dos pilares que o fundamentam.

Por isso, o modelo de racionalidade científica e/ou técnica, tão precioso no âmbito do paradigma da ciência moderna, tem sido amplamente questionado e deflagrado reflexões no âmbito da prática educativa, indicando a necessidade de se buscar outros fundamentos orientados a uma racionalidade plural, na qual o conhecimento científico possa ser uma experiência fascinante.

Tais pensamentos desencadearam o surgimento de um paradigma 'emergente', que leva em conta uma concepção 'pós moderna' de ciência, na medida em que estão presentes as contradições que o dito 'paradigma dominante' rejeita. O paradigma que ora emerge parece reconhecer a 'transição de paradigmas'.

Nesta perspectiva, segundo Santos (2000a:74), o paradigma emergente não é simplesmente uma revolução científica numa sociedade revolucionada pela ciência, mas sim um paradigma que se quer científico e social, ou melhor, 'um paradigma de um conhecimento prudente para uma vida decente'.

Contudo, o que seria um conhecimento prudente para uma vida decente? Quais são as proposições de um paradigma emergente? Que ideologia, crenças e valores éticos e morais podem-se assumir a partir do rompimento com o paradigma dominante ou de sua superação?

Buscar algumas reflexões - tendo como referência a prática educativa - que possam significar respostas a essas questões constitui o propósito deste trabalho. Para isso, utilizaremos a transcrição de gravações das discussões e observações por nós desenvolvidas a esse respeito, em situações acadêmicas, à guisa de compreensão dos paradigmas de conhecimento. Foi abordada a questão do 'paradigma emergente', (a) em termos eminentemente reflexivos em âmbito grupal e (b) em termos do depoimento de professores universitários em resposta à seguinte questão: 'Na sua prática, quer seja acadêmica ou pessoal, você percebe alguns indícios de mudança de paradigma? Tanto as discussões e observações quanto os depoimentos dos professores foram analisados à luz dos referenciais teóricos acessíveis nas obras de Boaventura de Sousa Santos.

\section{Refletindo sobre o paradigma dominante}

O que seria um paradigma prudente para uma vida decente, já que o paradigma dominante não se apresenta mais tão seguro e convincente? Com esse questionamento iniciamos nossas discussões, visando a encontrar pistas que nos permitissem entender o que caracterizaria tal paradigma na prática educativa, como também conceituá-lo (defini-lo). À medida que evoluíam as discussões, percebemos que não poderia haver um conceito ou uma definição clara e objetiva do que seria o paradigma emergente. Mas, como que dando uma resposta ao nosso questionamento e chamando a atenção às nossas concepções, Santos nos diz que (2000a: 74/75) "a configuração do paradigma que se anuncia no horizonte só pode obter-se por via especulativa". Sobre tais perspectivas, entendemos, em primeiro lugar, que elas estão de acordo com o processo histórico de construção do conhecimento dentro do paradigma dominante, o qual tem como perspectiva a fragmentação natureza/realidade em partes cada vez menores com o objetivo de conhecê-la e dominá-la. Essa perspectiva, no caso da educação, sempre esteve permeada pelos mecanismos de controle.

Em segundo lugar, que essas concepções também estão de acordo com o modelo hegemônico da racionalidade cognitiva-instrumental, geralmente assumido pelos sistemas educativos, quer sejam eles de ensino fundamental e médio, quer sejam de ensino superior. No caso do ensino superior, o modelo de formação profissional adotado pelas instituições consiste em problemas instrumentais, resolvidos mediante a aplicação rigorosa de técnicas e teorias científicas.

Por isso, entendemos também que as abstrações que geralmente orientam as ações ou as práticas educativas estão permeadas pela concepção epistemológica daquela racionalidade, que se contrapõe ao senso comum, recusando as orientações para a vida prática dele decorrentes; pressupõe 
que o conhecimento científico é a única forma válida de conhecimento; distancia teoria e prática, subordinando esta àquela e, com isso, restringindo as possibilidades de criatividade e responsabilidade; tende a reduzir o universo dos observáveis ao dos quantificáveis e o rigor do conhecimento ao rigor matemático do conhecimento, resultando na desqualificação cognitiva e social dos sujeitos que não operam com essa perspectiva; avança pela especialização e pela profissionalização do conhecimento, gerando uma relação íntima entre saber e poder, excluindo os sujeitos sociais que não produzem e nem manipulam o conhecimento científico e, com isso, acabam se assumindo como incompetentes cognitivamente e desarmados de poderes que o conhecimento científico proporciona aos que o detêm. (Bachelard apud Santos, 2000b: 34)

Desse modo, essas concepções influenciam não só no 'que' e 'como' os professores ensinam as disciplinas curriculares, mas também no significado que parecem atribuir às suas práticas pedagógicas. Além disso, em decorrência de tais concepções, os professores adquirem crenças e teorias sobre 'o que é' e 'como é' o ensino. Concepções que se refletem em seu modelo usual de ensino, vez que o professor - habituado à visão de aulas de caráter transmissivo e à reprodução passiva de conteúdos, teorias e conceitos científicos - lida com situações da prática de acordo com uma lógica padrão, cerceado pelas costumeiras respostas prontas e instrumentais.

Assim, a partir do que parece ter representado o paradigma dominante na prática educativa, compreendemos que a mudança ideacional que justifica a emergência de um paradigma que admita a diversidade e a diferença advém de rupturas com uma forma de pensar intransigente e unívoca.

\section{Um olhar sobre o paradigma emergente}

Com o intuito de buscarmos algumas reflexões que pudessem significar respostas às interrogações já enunciadas, as nossas discussões se dirigiram aos princípios para um paradigma emergente propos- tos por Boaventura. Apesar da recomendação desse autor de que, neste momento, não nos é possível visualizar projetos de pesquisa que correspondam inteiramente ao paradigma emergente, mas procurando corroborar tais reflexões, fomos investigar, junto a professores universitários, se há indícios de transição de paradigmática. A nosso ver, os depoimentos dos professores sugerem evidências de transição paradigmática:

... Apesar de ter estudado física quântica, cujo modelo de universo não é determinista e causal, trabalho na graduação com a física clássica newtoniana que, de certa forma, limita um tratamento mais holístico e transdisciplinar. ... Quanto à minha prática pessoal, percebo alguns indícios de mudança ao procurar entender mais as artificialidades da nossa relação com o outro, com nós mesmos e com a natureza. ... (Prof Flávia)

Tal depoimento sugere o primeiro princípio para um paradigma emergente, que reza - "todo o conhecimento científico-natural é científico social" -, pois, conforme expressa essa professora, parece haver uma tentativa de rompimento com uma forma de pensar dualista, pelo entendimento de que o sujeito biológico é também um sujeito social. $\mathrm{O}$ que nos parece também refletir tanto em sua vida pessoal quanto em sua atividade profissional. Isso porque, com base nesse princípio, a separação entre conhecimento científico-natural e o científico-social deixa de ter o valor que havia no paradigma dominante, refletindo na superação da visão dualista que, por muito tempo, foi considerada como insubstituível - sujeito/natureza.

Concluímos que o descobrimento desses conceitos, para derrubar os limites impostos pelo paradigma dominante nas concepções que orientam as nossas ações, só é possível pela abertura do diálogo às novas idéias e possibilidades.

$\bigcirc$ segundo princípio do paradigma emergente - "todo o conhecimento é local e total"- parecenos evidenciado no depoimento abaixo:

... momentos recém vividos por mim expressam indícios de mudança de paradigma no meu cotidiano 
acadêmico... Eram 19 professores, que tentavam uma "definição" conjunta de seus planos de ensino e de suas ações pedagógicas, explicitando os princípios teóricos e a visão de mundo que assumiam, levando em conta a 'diversidade' e buscando uma forma de ação 'integrada', um sabendo do que o outro faz e como o outro pensa. ...(Prof ${ }^{\mathrm{a}}$. Raquel)

Assim, parece-nos haver indícios de rompimento com a barreira da especialização, nas posturas de abertura do diálogo a outros pontos de vista, e de interação entre professores para a resolução de problemas educacionais.

Por isso, entendemos com Santos (1997) que a transição paradigmática está no reconhecimento de que a fragmentação do conhecimento impõe limites entre as disciplinas e reprime quem ou o que a queira, fazendo do especialista um ignorante proprietário de uma especialização, fechado ao diálogo e à abertura a outros pontos de vista e outras possibilidades, acarretando efeitos negativos que podem ser extensivos a toda uma comunidade. Desse modo, este princípio reconhece que o saber pode ter como perspectiva a totalidade universal e, mesmo assim, ser local, por constituir-se ao redor de temas, os quais podem ser adotados por grupos sociais concretos como projetos de vida locais.

Dentro dessa perspectiva, entendemos que, para a prática educativa, esse princípio pode romper com o que tem representado o conhecimento científico, tanto nas escolas quanto nas universidades: a fragmentação do saber em especialidades, que delimita um espaço de poder para quem as domina e restringe ou impede as interações entre as mesmas e os seus detentores, conseqüentemente impossibilita o projeto de uma educação emancipatória. Entendemos também que tal princípio pode auxiliar a superar as dificuldades sempre presentes no contexto educacional, entre as quais as relativas ao cultivo de "um único método científico" e de "uma só forma de conhecimento verdadeiro".

Os depoimentos, na nossa opinião, também estão de acordo com o terceiro princípio para o paradigma emergente, para o qual Santos propõe que "todo o conhecimento é autoconhe- cimento”. Nesse princípio, a transição paradigmática contempla a pluralidade de conhecimentos e a transgressão metodológica quanto ao estilo, permitindo, ao professor, uma maior personalização do seu trabalho, conduzindo-o à perspectiva de que todo conhecimento é autoconhecimento.

Nesse sentido, entendemos com Santos (1997:53) que, "no paradigma emergente, o caráter autobiográfico e auto referenciável da ciência é plenamente assumido".

Assim, entendemos que o conhecimento científico assume a esperança de um conhecimento solidário e compreensivo do mundo, e fomenta nossos desejos e perspectivas de como saber viver e atuar.

Com base nessa perspectiva, consideramos como Santos, que o conhecimento científico só tem sentido se fizer parte intrínseca do nosso modo de viver, traduzindo-se num saber prático. O que é perceptível no depoimento abaixo:

Pessoalmente, percebo uma forte tendência de abrir "conversações sobre tudo" o tempo todo, uma vez que os "fundacionais" encontram-se em xeque. Por outro lado, vai se tornando "consensual" a valorização das "incertezas" como instrumento de análise, bem como a necessidade de "melhor compreensão" do outro. A preocupação básica se volta para a idéia da "aprendizagem", ou de "como conhecer o conhecimento?".... (Prof. Marx)

Parece-nos, aqui, haver um processo de autoconhecimento e uma consciência dos limites, das possibilidades, das distorções, das teorias, das crenças e dos valores que orientam as ações, como também uma consciência do que valorizar e do que prescindir. Tal perspectiva leva ao quarto princípio - "todo o conhecimento visa constituir-se em senso comum". Com base nesse princípio, entendemos com Santos (2000a) que, para uma transição paradigmática, o conhecimento científico necessita ter um caráter emancipatório, visando constituir-se em senso comum, isso porque, "apesar do conhecimento do senso comum ser geralmente um conhecimento mistificado e mistificador, e apesar de ser conservador, possui uma dimensão utópica e liber- 
tadora que pode valorizar-se através do diálogo com o conhecimento pós-moderno".

\section{Rupturas epistemológicas: necessidade pedagógica}

Conclui-se que os princípios para um paradigma emergente interligam-se, objetivando uma revisão das reflexões negadas pelo paradigma dominante, reconhecendo a fundamental importância da transição para as mudanças e rupturas com ideologias, crenças, valores éticos e morais, especialmente na prática educativa.

A concepção epistemológica do paradigma dominante trouxe efeitos cruciais à educação, que sempre esteve permeada pelos mecanismos de controle e submissão, decorrentes da disciplinarização do conhecimento e da crença num único método e uma só forma de conhecimento verdadeiro, o que significou o cultivo ao individualismo, o fechamento ao diálogo e a uniformização do saber. Para a prática educativa, tais fatos determinaram o que os professores deveriam valorizar e o que deveriam prescindir em suas salas de aula, estabelecendo uma relação professor-transmissor/aluno-receptor.

Dentro dos princípios que orientam para um paradigma emergente, tais fatos podem ser contraditos, considerando que no cerne dos mesmos estão imbricadas questões como solidariedade, abertura ao diálogo, aceitação da multiplicidade de conhecimentos e das diferenças culturais.

Reconhecemos que a aplicação de tais princípios para uma transição paradigmática possa sofrer sérias limitações, tendo em vista a forte influência do paradigma dominante tanto na nossa constituição como sujeitos sociais, quanto profissionais. Mas também reconhecemos que tal aplicação pode ser possível a partir da consciência do que tem orientado as nossas concepções (ideologias, crenças, valores éticos e morais) e ações, pois, à medida que temos consciência delas, temos consciência dos nossos limites, das nossas possibilidades, das nossas distorções de ação na ação, das nossas teorias e dos nossos valores e, com isso, tomamos consciência do que temos prescindido e do que temos valorizado em nossa prática educativa.

\section{REFERÊNCIAS BIBLIOGRÁFICAS}

ARAGÃO, Rosália M. R. Reflexões sobre ensino, aprendizagem, conhecimento. Revista de Ciência e Tecnologia. Piracicaba, SP, v.2, n.3, p 7-12, 1993.

. In: ENDIPE, 10, 2000, Rio de Janeiro. Anais... Rio de Janeiro, 2000.

CHALMERS, A . F. O que é ciência afinal? São Paulo: Brasiliense, 1993.

CUNHA, Maria Isabel; LEITE, Denise B. C. Decisões pedagógicas e estruturas de poder na universidade. Campinas: Papirus, 1996. GALLO, Silvio. Disciplinaridade e Transversalidade. In: ENDIPE, 10, 2000, Rio de Janeiro. Anais... Rio de Janeiro, 2000.

Transversalidade e educação: pensando uma educação não disciplinar. In: ALVES, Nilda; GARCIA, Regina Leite (orgs.). O sentido da escola. Rio de Janeiro: DP\&A, 1999.

SANTOS, Boaventura de Sousa. A crítica da razão indolente: contra o desperdício da experiência. 2. ed. São Paulo: Cortez, 2000. (a).

Introdução a uma ciência pós-moderna. 3. ed. Rio de Janeiro: Graal, 2000. (b).

Um discurso sobre as ciências. 9. ed. Porto: Afrontamento, 1997.

Para uma pedagogia do conflito. Texto. 